DOI: $10.1515 / \mathrm{amm}-2016-0307$

\author{
M. TENEROWICZ*, M. SUŁOWSKI*,\#
}

\title{
FRACTOGRAPHY OF SINTERAUSTEMPERED AND SINTERHARDENED Fe-3Mn-0.8C PM STEELS
}

Sintered steels with the addition of manganese are widely used in industry because of their attractive mechanical properties. The main problem of using manganese in powder metallurgy steel production is its high affinity for oxygen. The choice of proper sintering parameters can significantly improve the properties of the final product.

For the present investigations Höganäs iron powder grade NC 100.24, low-carbon $(1.3 \% \mathrm{C})$ ferromanganese Elkem (Eramet Norway Sauda - formerly Elkem Manganese Sauda) and graphite powder grade C-UF were used as the starting powders. Mixture of powders, containing 3\% Mn and $0.8 \% \mathrm{C}$, was prepared in Turbula mixer for 30 minutes. Following mixing, "dog bone" compacts were pressed at $660 \mathrm{MPa}$ according to PN-EN ISO 2740 standard. Sintering of compacts was carried out in the laboratory tube furnace at 1120 and $1250^{\circ} \mathrm{C}$ for 60 minutes in air or pure nitrogen $(99.999 \% \mathrm{~N} 2)$. The present investigation deals with the comparison of two heat treatment routes: sinterhardening (SH) and sinteraustempering (SAT), carried out both in air and pure nitrogen. Mechanically tested steels were investigated using JEOL JSM 700F completed with EDS. Metallography tests were carried out on 3\% Nital etched samples.

In this paper the results of mechanical tests and metallography and fractography investigations are shown. According to the results obtained, it can be assumed that for sinteraustempering higher temperature does not influence mechanical properties of sintered steels. For both methods using pure nitrogen as sintering atmosphere gave better results.

Keywords: sinteraustempering, sinterhardening, fractography, PM manganese steels

\section{Introduction}

Sintered steels with manganese are widely used in industry because of its attractive mechanical properties. Following the data presented in $[1,2]$, the addition of manganese increases hardness and tensile strength of steels and decreases their elongation (Fig. 1).

Manganese very often substitutes carcinogenic nickel.

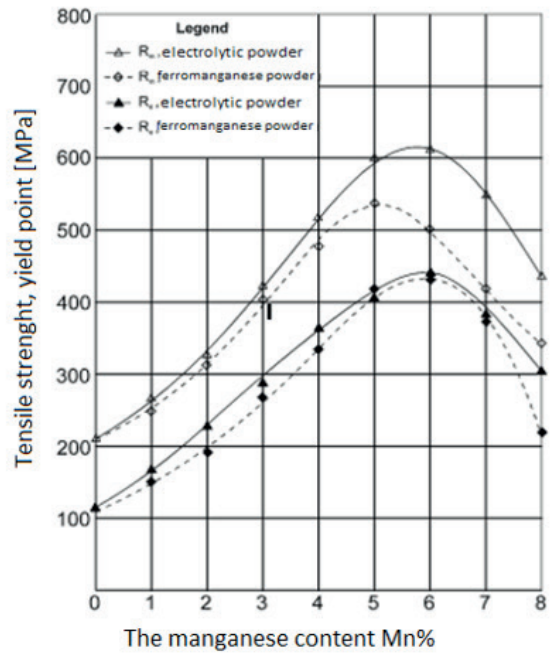

a)
The main problem of using manganese is the high affinity of manganese for oxygen and high vapour pressure of Mn at the sintering temperature. Therefore, this element is introduced during sintering in the form of ferroalloy. Sintering process is usually carried out in reducing atmosphere with a low dew point [3]. As was presented in [4-10], first attempts of sintering this steels in air were very promising.

Manganese steels belongs to the medium-to-high strength

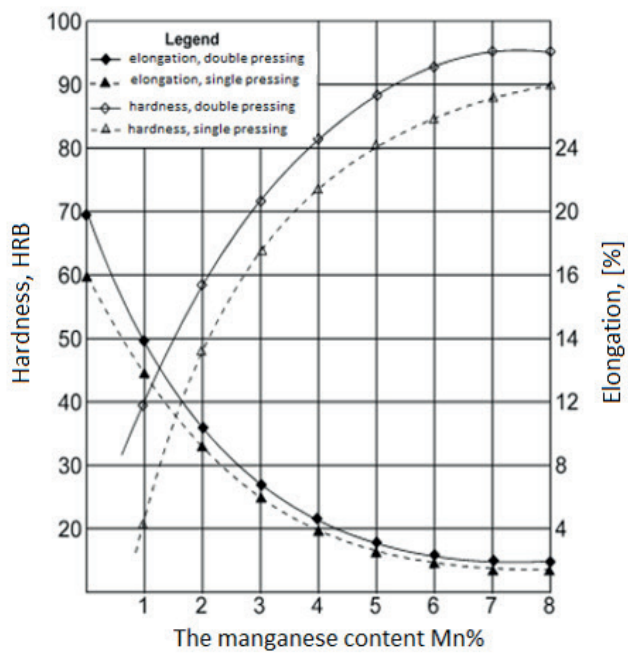

b)

Fig. 1. The effect of Mn content on: a) TRS and $\mathrm{R}_{0,2}, \mathrm{~b}$ ) hardness and elongation of single pressed steels $[1,2]$

* AGH UNIVERSITY OF SCIENCE AND TECHNOLOGY, FACULTY OF METALS ENGINEERING AND INDUSTRIAL COMPUTER SCIENCE, DEPARTMENT OF PHYSICAL METALLURGY \& POWDER METALLURGY, AL. A. MICKIEWICZA 30, 30-059 KRAKÓW, POLAND

\# corresponding author: sulek@agh.edu.pl 


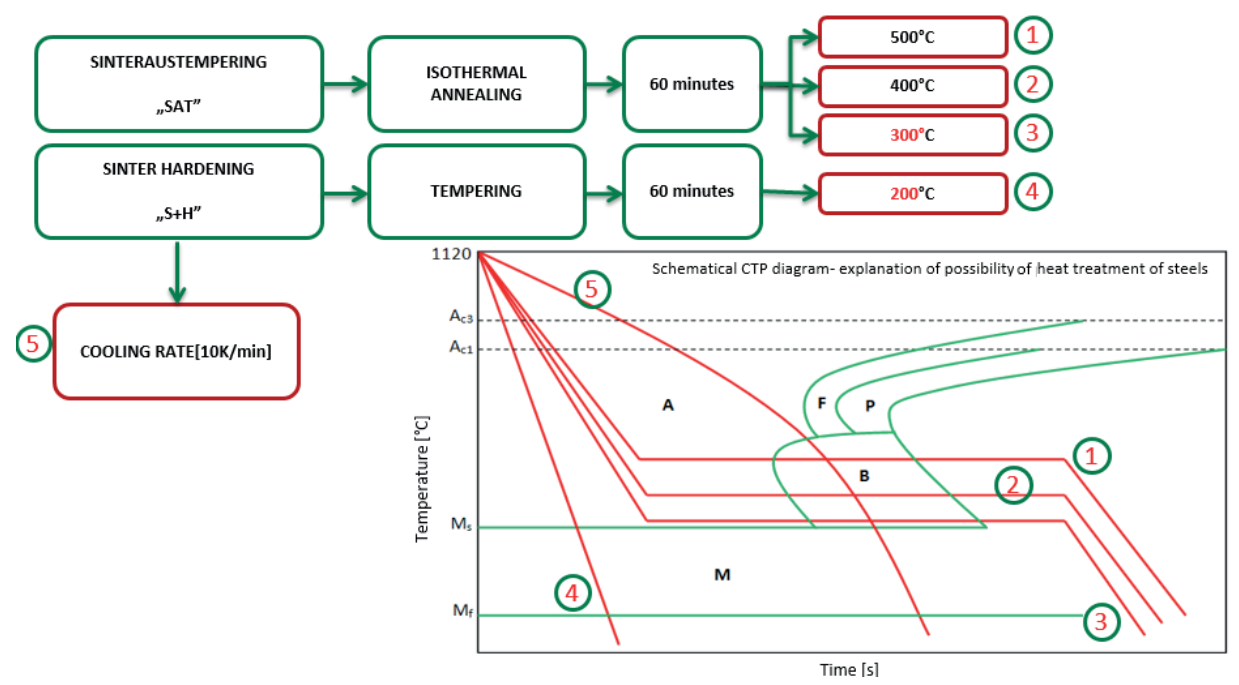

Fig. 2. The scheme of heat treatments on a TTT diagram [12]

steels and are characterized by very high hardenability. Because of it, those steels could be processed by sinterhardening very fast cooling from sintering temperature and subsequent tempering at approx. $200^{\circ} \mathrm{C}$ for 60 minutes [11]. This heat treatment allows the steel to obtain the proper combination of strength and plastic properties.

At present, on an industrial scale, increasing the cost production of steels using post sintering operation, e.g. tempering, is not economic. To obtain good mechanical properties of sintered steels without increasing the production cost, sinteraustempering was proposed. This technique is a quite new method of heat treatment of PM parts and was proposed by Molinari for low alloyed steels. It was also introduced by Fiał et al [12] for laboratory scale production of Mn- and Cr- containing PM steels (Fig. 2).

As was presented in Fig. 2, sinterhardening is a cooling process from the sintering temperature, without annealing, to room temperature and then tempering at $200^{\circ} \mathrm{C}$. For sinteraustempering, the steel is cooled down rapidly from the sintering temperature to the bainitic region, then isothermally annealed to complete the bainitic transformation and subsequently cooled to room temperature. The resulting steel with a bainitic structure is less hard than steel hardened to martensite, but also more ductile than steel obtained by quenching and tempering to the same hardness.

\section{Experimental}

Höganäs iron powder grade NC 100.24, low-carbon ferromanganese Elkem (Eramet Norway Sauda - formerly Elkem Manganese Sauda) and graphite powder grade C-UF were used as starting powders. Mixture of powders, containing $3 \% \mathrm{Mn}$ and $0.8 \% \mathrm{C}$ was prepared in Turbula mixer for 30 minutes. Following mixing, "dog bone" compacts were pressed at $660 \mathrm{MPa}$ according to PN-EN ISO 2740 standard. To minimize friction coefficient, zinc stearate was used as a lubricant and was applied on the punches before pressing each sample. The samples were numbered from B1 to B20 depending on the processing variant.
Sintering of compacts was carried out in a semi-closed container, proposed by A. Ciaś [14], in a laboratory tube furnace at $1250^{\circ} \mathrm{C}$ for 60 minutes in air (B1 - B10) or in pure nitrogen (B11 - B20). The heating rate to sintering temperature was approx. $75^{\circ} \mathrm{C} / \mathrm{min}$. During sintering in air, lumps of ferromanganese were placed into the boat together with the green compacts.

Samples B1-B5, B11-B15 and B6-B10, B16-B20 were sinteraustempered and sinterhardened, respectively. Cooling rate was approx. $66^{\circ} \mathrm{C} / \mathrm{min}$., regardless of the heat treatment variant. Annealing in the bainitic zone (SAT $300^{\circ} \mathrm{C}$ ) was for 60 minutes. After it, specimens were cooled to room temperature. To compare the results, sintering of green compacts was carried out at $1120^{\circ} \mathrm{C}[15,16]$ using the same sintering atmospheres. Samples numbered from P11 to P20 were sinteraustempered and samples numbered from P1 to P10 - sinterhardened. To compare the results obtained, samples no: P2, P8, P13, P18 and B3, B6, B12, B20 were selected.

After sintering, samples were mechanically tested (UTS, A, TRS, hardness and microhardness). Following mechanical tests, metallographic (LOM) and fracture investigations (SEM) were carried out using Leica DM 4000M and JEOL JSM 700F equipped with EDS, respectively.

\section{Results}

The results of mechanical properties are summarized in Tables 1 and 2. The highest tensile strength, UTS, was reported for sample B16 - $745 \mathrm{MPa}$. The lowest value of UTS, 467 $\mathrm{MPa}$, was recorded for sample B10. The highest average of UTS, $622 \mathrm{MPa}$, was obtained for groups of samples B16-B20 in comparison with the lowest UTS mean value - $527 \mathrm{MPa}$ calculated for samples B1-B5. The greatest tensile elongation (A\%) was recorded for sample B10 (3.89\%), the smallest one - for sample B3 (1.08\%).

The highest bend strength, TRS (Table 1) was recorded for sample B17 (1471 MPa). On the other hand, the lowest TRS was obtained for sample B10 (895 MPa). The highest and the lowest average TRS values were obtained for groups 
TABLE 1

Mechanical properties of the investigated steels

\begin{tabular}{|c|c|c|c|c|c|c|c|}
\hline \hline No of samples & $\begin{array}{c}\text { Mean height, } \\
{[\mathrm{mm}]}\end{array}$ & Width, $[\mathrm{mm}]$ & $\begin{array}{c}\text { Sintered density, } \\
{\left[\mathrm{g} / \mathrm{cm}^{3}\right]}\end{array}$ & UTS, $[\mathrm{MPa}]$ & $\begin{array}{c}\text { A after tensile } \\
\text { test, }[\%]\end{array}$ & $\begin{array}{c}\mathrm{R}_{0,2} \text { yield offset, } \\
{[\mathrm{MPa}]}\end{array}$ & TRS, $[\mathrm{MPa}]$ \\
\hline B1 & 5.92 & 5.85 & 6.66 & 562 & 2.01 & 526 & 1423 \\
\hline B2 & 5.94 & 5.85 & 6.65 & 468 & 1.29 & 395 & 1205 \\
\hline B3 & 5.91 & 5.85 & 6.66 & 502 & 1.08 & - & 1283 \\
\hline B4 & 5.94 & 5.87 & 6.65 & 484 & 1.54 & 447 & 1451 \\
\hline B5 & 6.01 & 5.83 & 6.58 & 619 & 2.09 & 494 & 1162 \\
\hline B6 & 5.98 & 5.86 & 6.61 & 602 & 1.87 & 571 & 1125 \\
\hline B7 & 6.00 & 5.87 & 6.58 & 608 & 2.22 & 580 & 1339 \\
\hline B8 & 6.06 & 5.87 & 6.88 & 567 & 1.80 & 491 & 1135 \\
\hline B9 & 6.06 & 5.89 & 7.00 & 602 & 2.17 & 549 & 1090 \\
\hline B10 & 6.12 & 5.89 & 6.94 & 467 & 3.89 & 427 & 895 \\
\hline B11 & 6.25 & 5.85 & 6.33 & 559 & 1.88 & 400 & 1108 \\
\hline B12 & 5.99 & 5.86 & 6.60 & 591 & 2.13 & 112 & 1204 \\
\hline B13 & 6.01 & 5.84 & 6.58 & 690 & 2.29 & 564 & 1343 \\
\hline B14 & 6.02 & 5.84 & 6.57 & 640 & 2.73 & 562 & 1055 \\
\hline B15 & 6.03 & 5.86 & 6.57 & 582 & 1.83 & - & 1189 \\
\hline B16 & 6.03 & 5.85 & 6.54 & 745 & 3.19 & 571 & 1048 \\
\hline B17 & 5.98 & 5.87 & 6.62 & 686 & 2.93 & 645 & 1471 \\
\hline B18 & 6.00 & 5.85 & 6.58 & 567 & 1.82 & 483 & 1140 \\
\hline B19 & 6.09 & 5.84 & 6.49 & 532 & 1.76 & 531 & 1070 \\
\hline B20 & 5.99 & 5.86 & 6.60 & 584 & 1.91 & 526 & 1266 \\
\hline
\end{tabular}

of samples B1-B5 (1305 MPa) and B6-B10 (1117 MPa), respectively.

Mechanical properties of chosen samples

\begin{tabular}{|c|c|c|c|c|}
\hline \hline Sintering variant & Sample & $\begin{array}{c}\text { Mean hardness, } \\
\text { HV 30 }\end{array}$ & $\begin{array}{c}\text { UTS, } \\
{[\mathrm{MPa}]}\end{array}$ & $\begin{array}{c}\text { TRS, } \\
{[\mathrm{MPa}]}\end{array}$ \\
\hline $\mathrm{SH} / 1120^{\circ} \mathrm{C} /$ air & P2 & 213 & 577 & 1608 \\
\hline $\mathrm{SH} / 1250^{\circ} \mathrm{C} /$ air & B6 & 246 & 602 & 1125 \\
\hline $\mathrm{SH} / 1120^{\circ} \mathrm{C} / \mathrm{N} 2$ & P8 & 218 & 650 & 1803 \\
\hline $\mathrm{SH} / 1250^{\circ} \mathrm{C} / \mathrm{N} 2$ & $\mathrm{~B} 20$ & 261 & 584 & 1266 \\
\hline $\mathrm{SAT} / 1120^{\circ} \mathrm{C} /$ air & $\mathrm{P} 13$ & 224 & 565 & 1099 \\
\hline $\mathrm{SAT} / 1250^{\circ} \mathrm{C} /$ air & $\mathrm{B} 3$ & 227 & 502 & 1283 \\
\hline $\mathrm{SAT} / 1120^{\circ} \mathrm{C} / \mathrm{N} 2$ & $\mathrm{P} 18$ & 220 & 624 & 1749 \\
\hline $\mathrm{SAT} / 1250^{\circ} \mathrm{C} / \mathrm{N} 2$ & $\mathrm{~B} 12$ & 224 & 591 & 1204 \\
\hline
\end{tabular}

Hardness of sintered steels was measured in 5 points on each sample as was shown in Fig. 3.

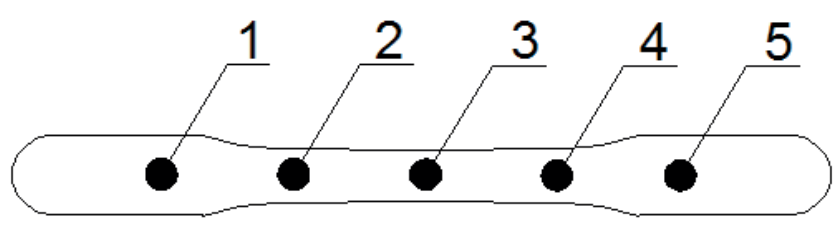

Fig 3. Measuring points for the hardness test

For each sample mean hardness was calculated. Based on the results of hardness measurements, presented in Table 2, it was observed that for the sinteraustempered materials, the mean hardness for the whole group was slightly lower than for the group of materials made using sinterhardening, but the mean hardness values were more aligned. The highest mean hardness achieved for sample B20 - 261 HV 30.

Microhardness tests were carried out on four samples coded: B3, B6, B12, B20 using an Innovar Hardness Tester. The hardness was measured on the cross-surface alond the pressing direction.

The sample selection depended on the results obtained during static bend tests. 12 measurements were made for each sample. The results of microhardness measurements are shown in Table 3.

TABLE 3

Results of microhardness test

\begin{tabular}{|c|c|c|c|c|}
\hline \hline \multirow{2}{*}{ Measured point } & \multicolumn{4}{|c|}{ No of samples } \\
\cline { 2 - 5 } & B3 & B12 & B6 & B20 \\
\hline 1 & 307.9 & 245.3 & 178.3 & 298.1 \\
\hline 2 & 231.4 & 403.6 & 165 & 267.5 \\
\hline 3 & 145.7 & 313.7 & 228.2 & 395.3 \\
\hline 4 & 339.8 & 294 & 311.1 & 579.3 \\
\hline 5 & 186.4 & 307.9 & 393.9 & 240.5 \\
\hline 6 & 214 & 329.1 & 287.1 & 317.9 \\
\hline 7 & 321.9 & 340.8 & 342.3 & 506.7 \\
\hline 8 & 254.3 & 458.1 & 224.8 & 569.7 \\
\hline 9 & 319.9 & 170 & 572.1 & 585 \\
\hline 10 & 273.2 & 328.4 & 480.6 & 228 \\
\hline 11 & 232.4 & 295.8 & 261.7 & 315.6 \\
\hline 12 & 306.7 & 179.2 & 293.4 & 257.9 \\
\hline Mean value & 261 & 305.4 & 311.54 & 380 \\
\hline
\end{tabular}


Air

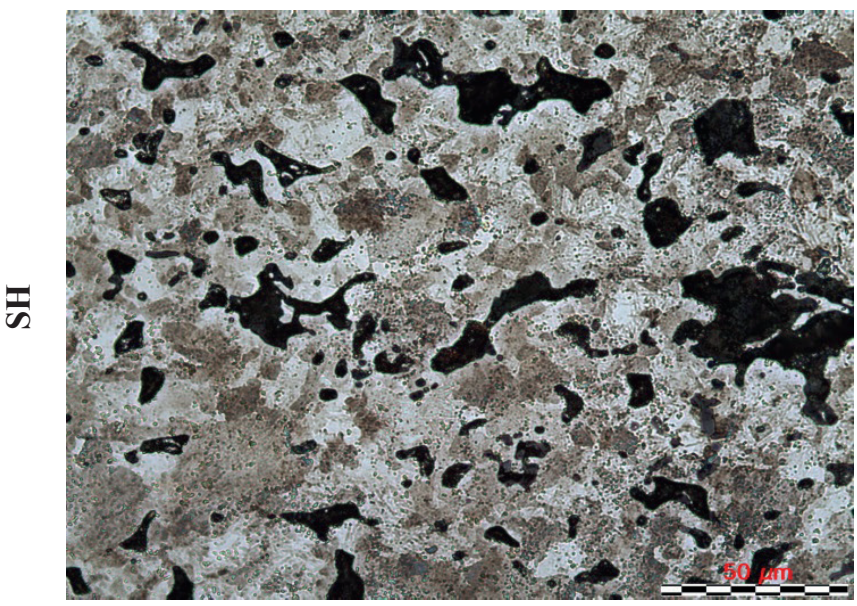

a)

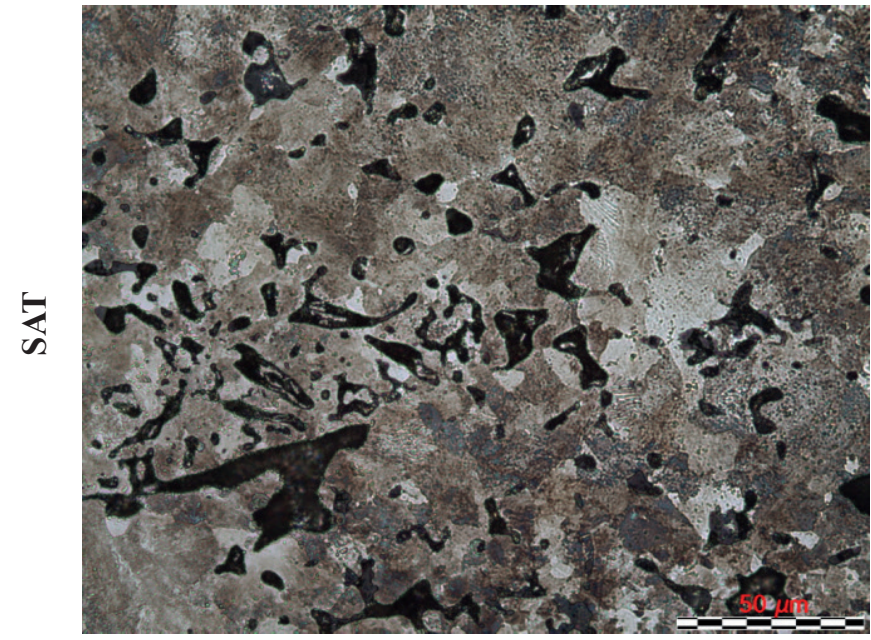

c)
N2

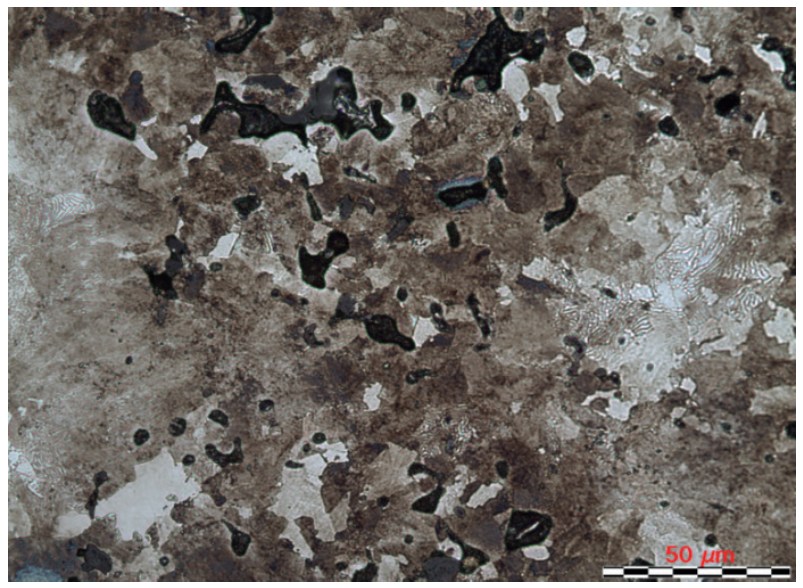

b)

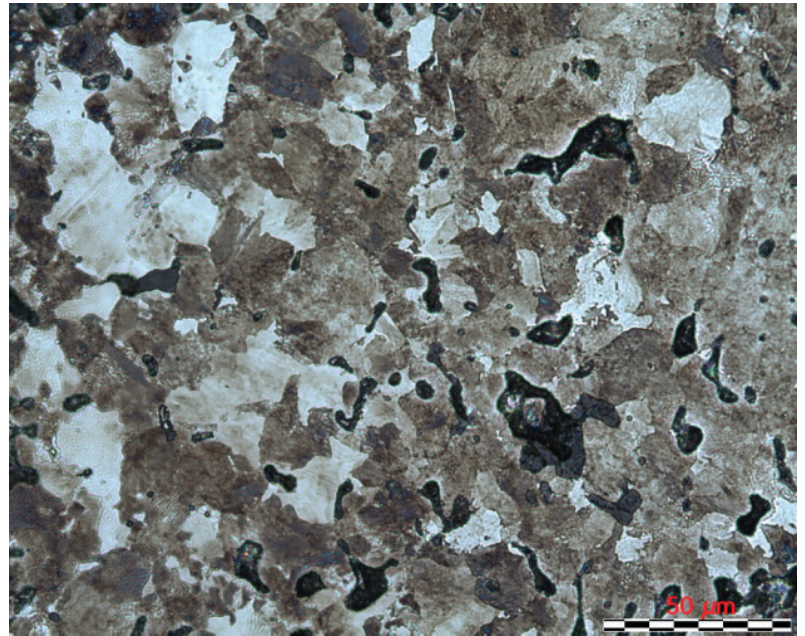

d)

Fig. 4. Microstructure of samples: a) P2, b) P8, c) P13, d) P18

Following the results presented in Table 3, the lowest

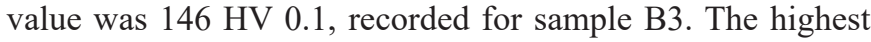
microhardness was recorded for sample B20 - 585 HV 0.1.

The microstructures of investigated steels are shown in Figs. 3-10. Metallographic observations were made on samples P2, P8, P12, P18 and B3, B6, B12, B20 using Leica DM4000M microscope.

After sintering at the lower temperature $\left(1120^{\circ} \mathrm{C}\right)$, sample P2 (Fig. 4a) was characterized by a microstructure consisting of ferrite and pearlite, with a small amount of bainite. In the structure of sample P8 (Fig. 4b) pearlite prevailed. Microstructure of sintered P13 and P18 steels (SAT - Figs. 4c, 4d), regardless of the sintering atmosphere, was pearlitic with a small amount of bainite and martensite and a large number of pores.

After sintering at $1250^{\circ} \mathrm{C}$, the microstructure of sample
B3 (Fig. 5a) consisted of ferrite (light regions) and pearlite (dark areas). In the other samples from group "B" (B6, B12, B20 - Figs. 5b-5d), microstructure mainly consisted of martensite; in the structure of the samples B6 and B12 bainite was also observed. In the sample B20 (Fig. 5d), in addition to martensite, retained austenite was observed.

Fractography analysis was carried out on $\mathrm{B}$ and $\mathrm{P}$ series samples (B3, B6, B12, B20, P2, P8, P13 and P18, accordingly to production variant). In sample $\mathrm{P} 2\left(1120^{\circ} \mathrm{C} / \mathrm{SH} /\right.$ air variant), large oxides were observed. In point 1 (Spectrum 1 - Fig. 6a), the analysis showed the presence of undissolved particles of manganese (79 wt.\% Mn - Fig. 6c). In this sample cleavage appeared. Cleavage occurred mainly when the structure consisted of pearlite or bainite. The presence of plastic deformation indicates the presence of plastic flow in the form of intergranular necks. 
Sintering temperature $1250^{\circ} \mathrm{C}$

Air

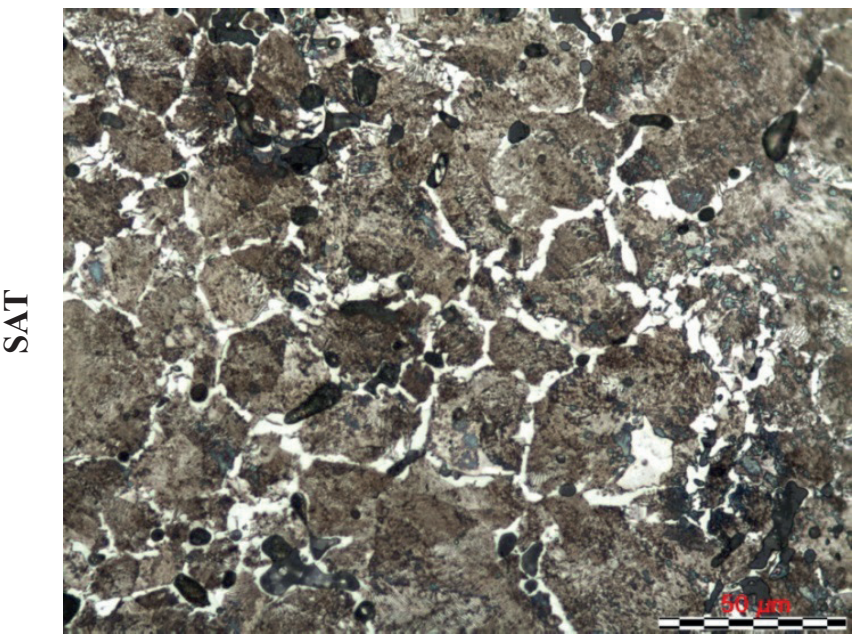

a)

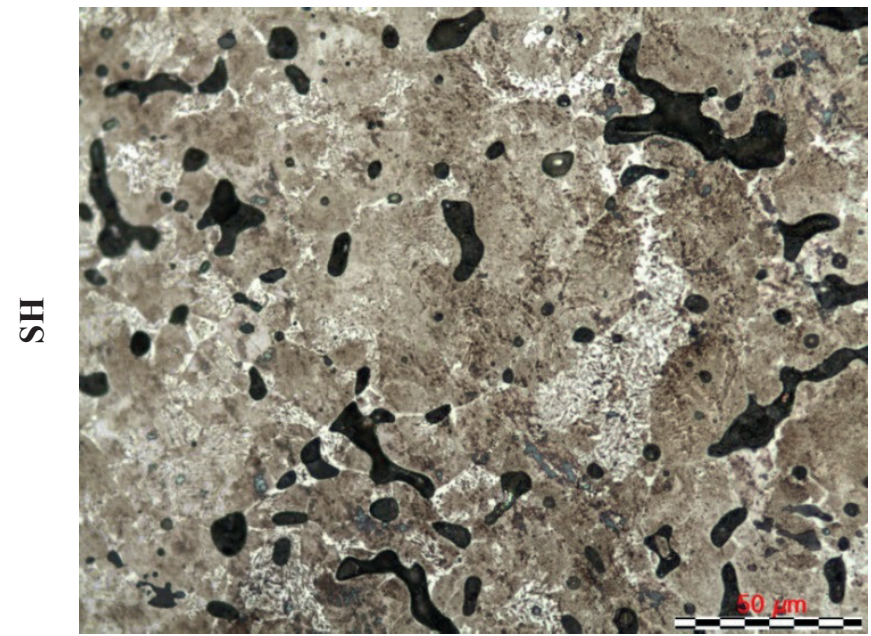

c)
N2

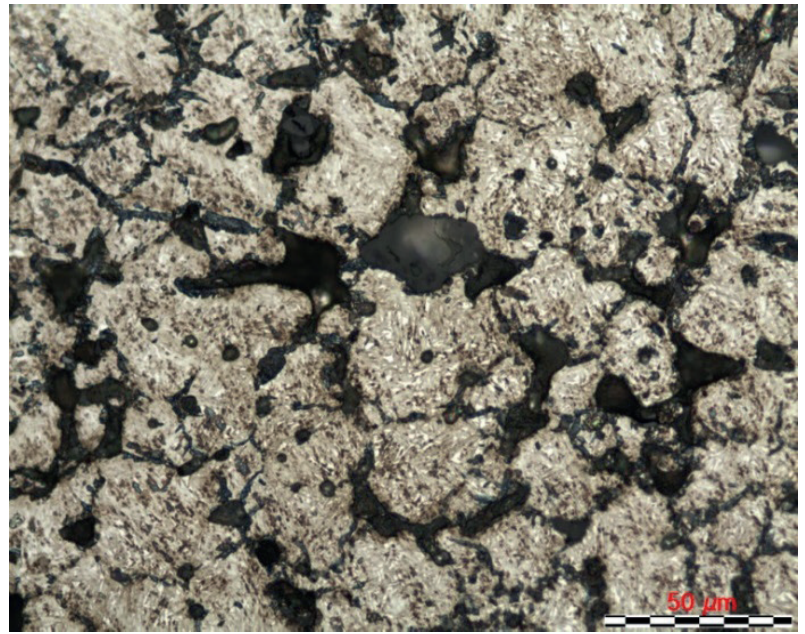

b)

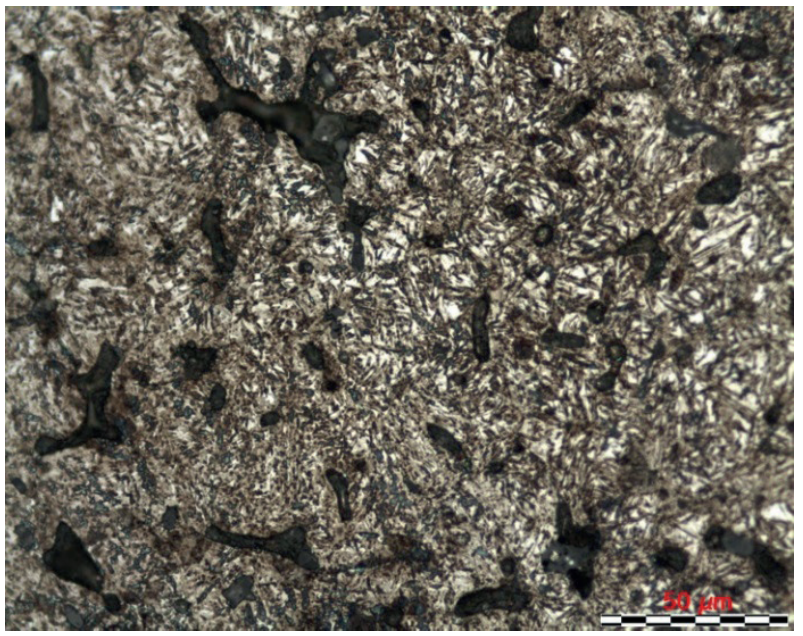

d)

Fig. 5. Microstructure of samples: a) B3, b) B12, c) B6, d) B20

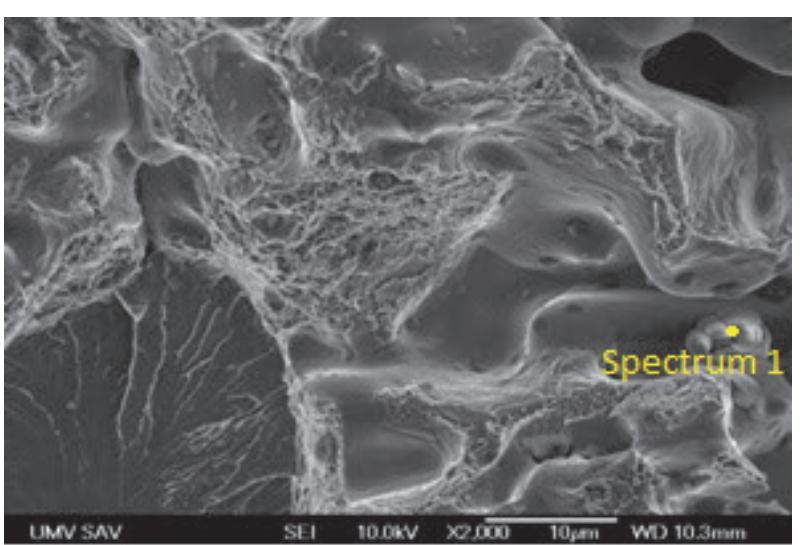

a)

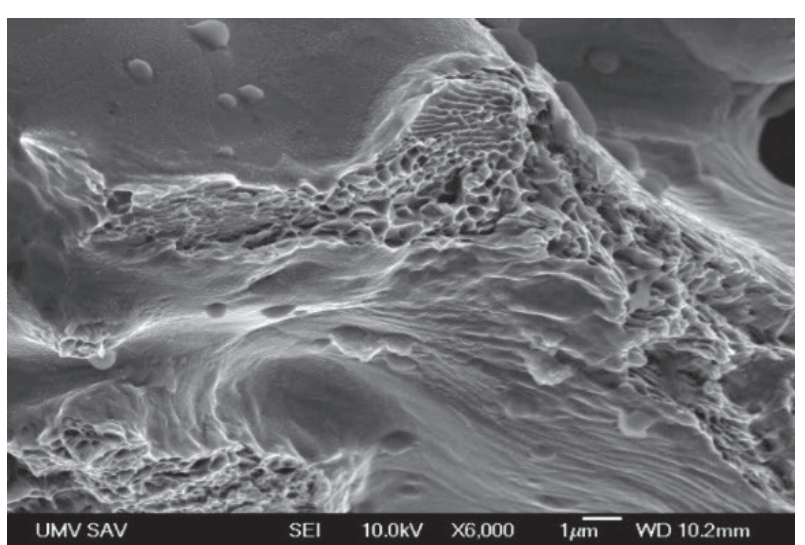

b)

\begin{tabular}{|c|c|c|}
\hline \multirow{2}{*}{ Spectrum 1 } & \multicolumn{2}{|c|}{ Element } \\
\cline { 2 - 3 } & wt.-\% & at.-\% \\
\hline $\mathrm{Mn}$ & 79.59 & 79.85 \\
\hline $\mathrm{Fe}$ & 20.41 & 20.15 \\
\hline
\end{tabular}

c)

Fig. 6. Fractography of sample P2: a) river pattern in the left corner, b) dimples as the evidence of ductile fracture, c) EDS analyses 
In sample P8 (Fig. 7), which was produced using $1120^{\circ} \mathrm{C} /$ $\mathrm{SH} / \mathrm{N} 2$ variant, intergranular fracture occurred due to the high content of oxides, often forming clusters (Fig. 7b). In areas free of oxides, dimples as an evidence of ductile fracture were observed (Fig. 7a). There were also remnants of undissolved ferromanganese particles.

Analysis of chemical composition of sample $\mathrm{P} 13\left(1120^{\circ} \mathrm{C} /\right.$ SAT/air) (Spectrum 3 - Fig. 8b, 8c, 8d) showed the presence of impurities in the material (e.g. silicon up to $8 \%$ by weight). Some areas of the sample were free of oxides and in some clusters of oxides were observed (Fig. 8a).

The last sample observed was P18, prepared according to $1120^{\circ} \mathrm{C} / \mathrm{SAT} / \mathrm{N} 2$ variant (Fig. 9). It was interesting to observe a large nitride (in the left corner on the photograph). In addition, large amount of brittle intergranular fracture and the presence of manganese oxides was observed (Spectrum 2 - Fig. 9b, 9c).

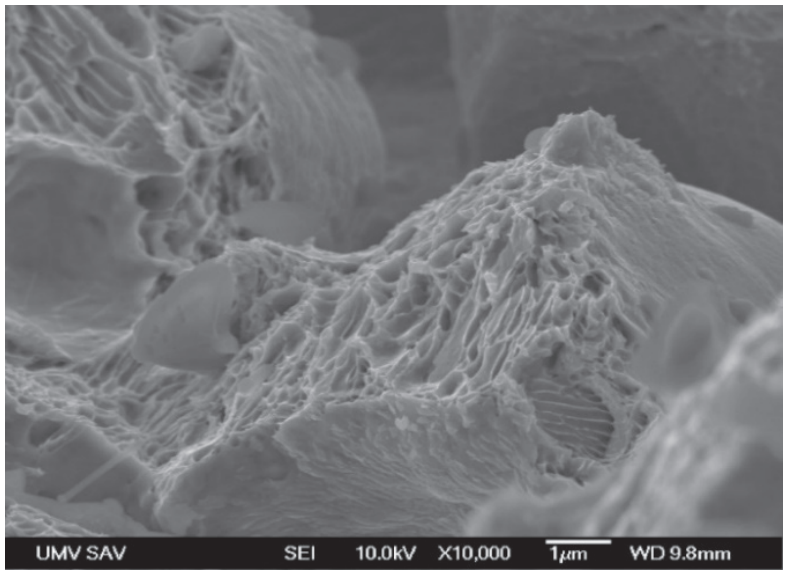

a)

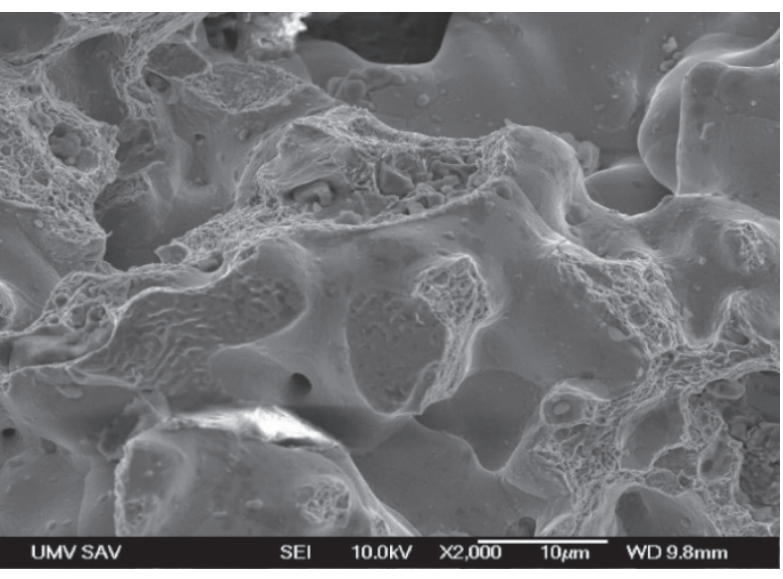

b)

Fig. 7. Fractography of sample P8: a) shallow dimples, b) oxide agglomeration

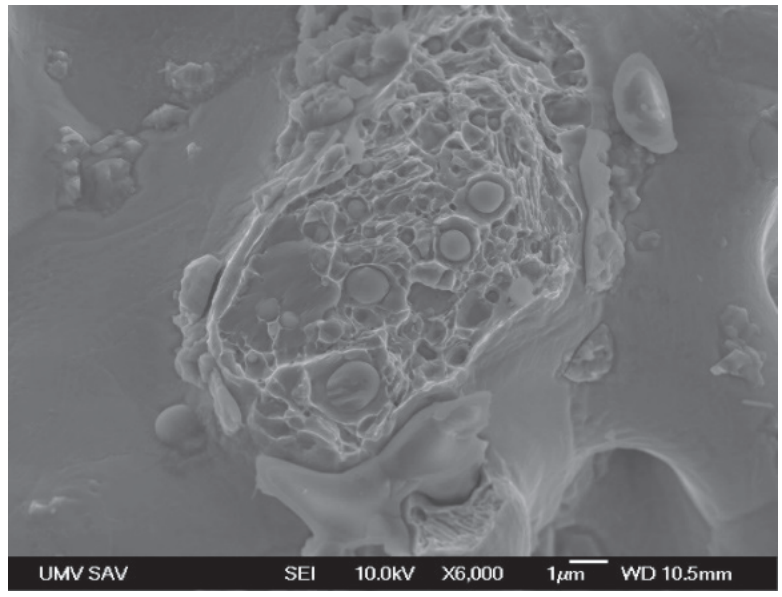

a)

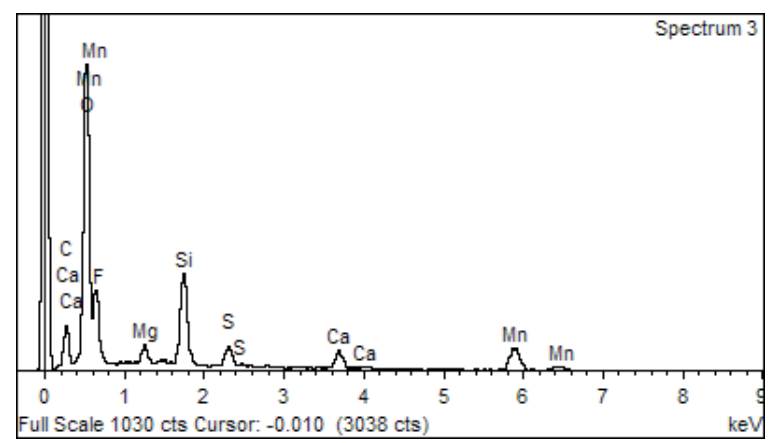

c)

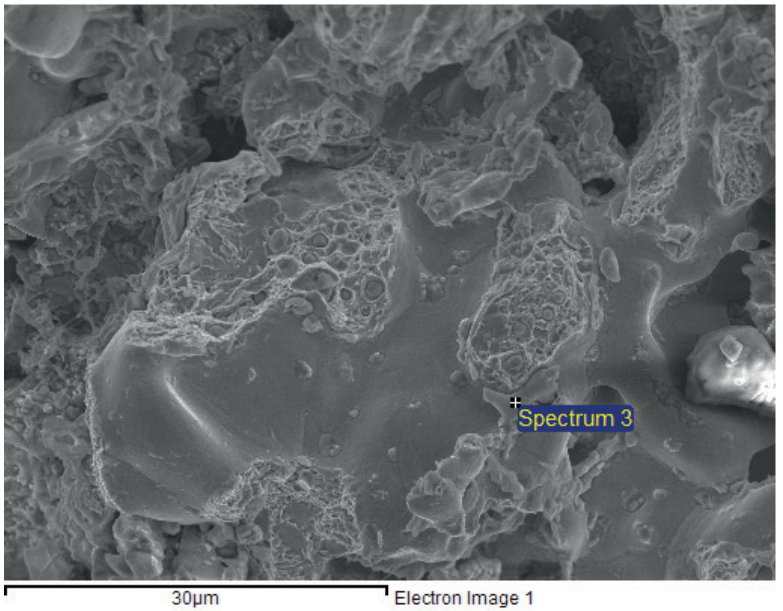

b)

\begin{tabular}{|c|c|c|}
\hline \multirow{2}{*}{ Spectrum 3 } & \multicolumn{2}{|c|}{ Element } \\
\cline { 2 - 3 } & wt.-\% & at.-\% \\
\hline $\mathrm{C}$ & 9.36 & 18.85 \\
\hline $\mathrm{O}$ & 28.63 & 43.28 \\
\hline $\mathrm{F}$ & 5.25 & 6.68 \\
\hline $\mathrm{Mg}$ & 1.68 & 1.67 \\
\hline $\mathrm{Si}$ & 8.60 & 7.41 \\
\hline $\mathrm{S}$ & 2.71 & 2.04 \\
\hline $\mathrm{Ca}$ & 4.85 & 2.93 \\
\hline $\mathrm{Mn}$ & 38.92 & 17.14 \\
\hline
\end{tabular}

d)

Fig. 8. Fractography of P13 sample: (a) large agglomeration of oxides in the centre of the photograph, EDS analyses with table of spectrum 3 (b, c, d) 


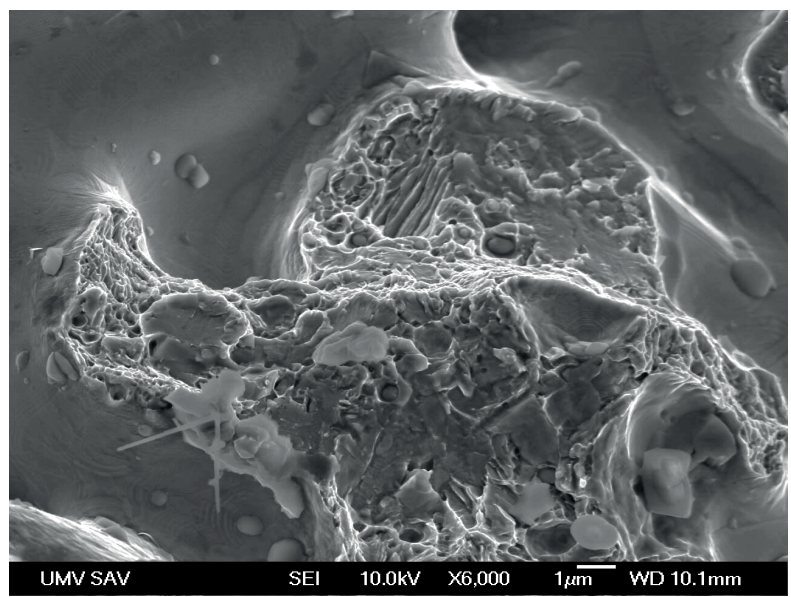

a)

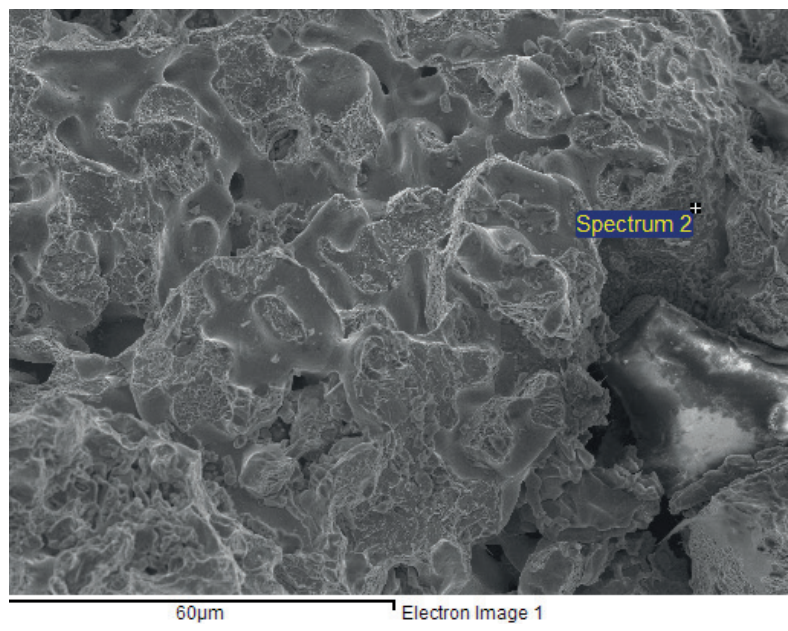

b)

\begin{tabular}{|c|c|c|}
\hline \multirow{2}{*}{ Spectrum 2 } & \multicolumn{2}{|c|}{ Element } \\
\cline { 2 - 3 } & wt.-\% & at.-\% \\
\hline C & 1.53 & 6.39 \\
\hline $\mathbf{O}$ & 1.95 & 6.11 \\
\hline $\mathbf{M g}$ & 0.64 & 1.32 \\
\hline $\mathbf{M n}$ & 8.65 & 7.89 \\
\hline $\mathbf{F e}$ & 87.23 & 78.29 \\
\hline
\end{tabular}

c)

Fig. 9. Fractography of sample P18: nitrides in left corner (a), spectrum 2 from EDS analyses (b, c)

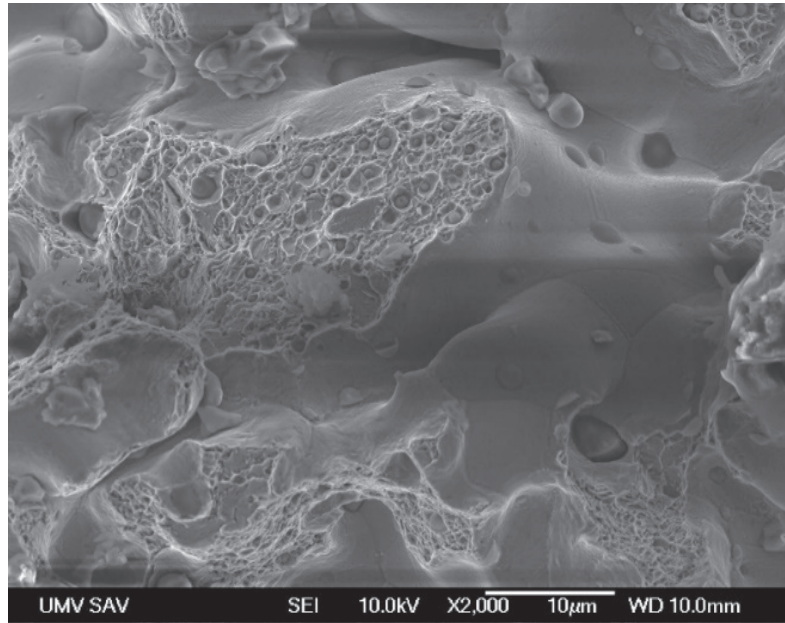

a)

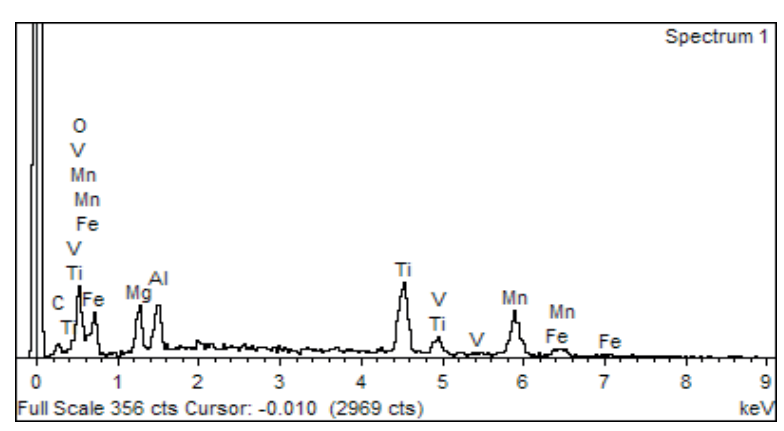

c)

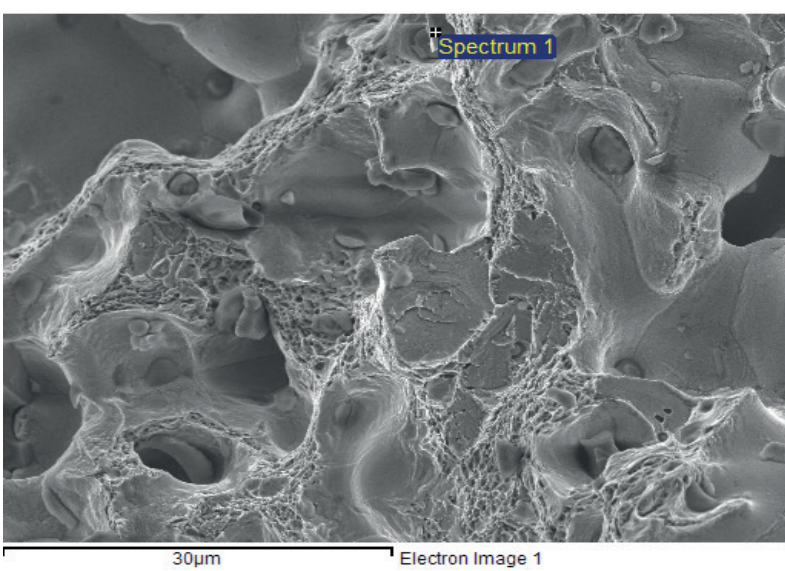

b)

\begin{tabular}{|c|c|c|}
\hline \multirow{2}{*}{ Spectrum 1 } & \multicolumn{2}{|c|}{ Element } \\
\cline { 2 - 3 } & wt.-\% & at.-\% \\
\hline $\mathbf{C}$ & 4.11 & 7.55 \\
\hline $\mathbf{O}$ & 36.16 & 49.86 \\
\hline $\mathbf{F}$ & 4.04 & 4.69 \\
\hline $\mathbf{M g}$ & 18.30 & 16.61 \\
\hline $\mathbf{S i}$ & 15.57 & 12.23 \\
\hline $\mathbf{C a}$ & 2.03 & 1.12 \\
\hline $\mathbf{M n}$ & 19.78 & 7.94 \\
\hline
\end{tabular}

d)

Fig. 10. The fractography of sample B3 (a) with EDS analyses (b, c, d) 
In sample $\mathrm{B} 3\left(1250^{\circ} \mathrm{C} / \mathrm{SAT} / \mathrm{air}\right)$, the presence of large quantities of oxides forming a uniform cluster was observed (Fig. 10a). Another evidence for the presence of large amounts of oxides are the chemical analysis results shown in Figs. 10c and $10 \mathrm{~d}$, with microareas wherein the oxygen content is up to 36.16 wt.-\% (Fig. 10d).

After changing the production variant from $1250^{\circ} \mathrm{C} /$ $\mathrm{SH} / \mathrm{N} 2$ to $1250^{\circ} \mathrm{C} / \mathrm{SH} /$ air (sample $\mathrm{B} 6$ ) the occurrence of intergranular cracks (Fig. 11) as well as higher oxide content were noticed. The sample was characterised by brittle fracture.
In the sample B12, sintered according to $1250^{\circ} \mathrm{C} / \mathrm{SAT} /$ $\mathrm{N} 2$ variant, a more brittle than ductile fracture was observed. The sample failed in an intergranular way. The chemical composition analysis (Spectrum 2 - Figure 11b) showed a high carbon content ( $61.22 \%$ by mass - Fig. $12 \mathrm{c})$.

In the sample B20 $\left(1250^{\circ} \mathrm{C} / \mathrm{SH} / \mathrm{N} 2\right)$ the chemical analysis point Spectrum 2 (Fig. 13) showed a high content of oxygen (oxide of $\mathrm{Mn}$ ) and the presence of brittle fracture. In this sample there was also a large amount of impurities $(\mathrm{Na}, \mathrm{Mg}$, $\mathrm{Si}, \mathrm{S}, \mathrm{Ca}, \mathrm{Ti}, \mathrm{Al})$.

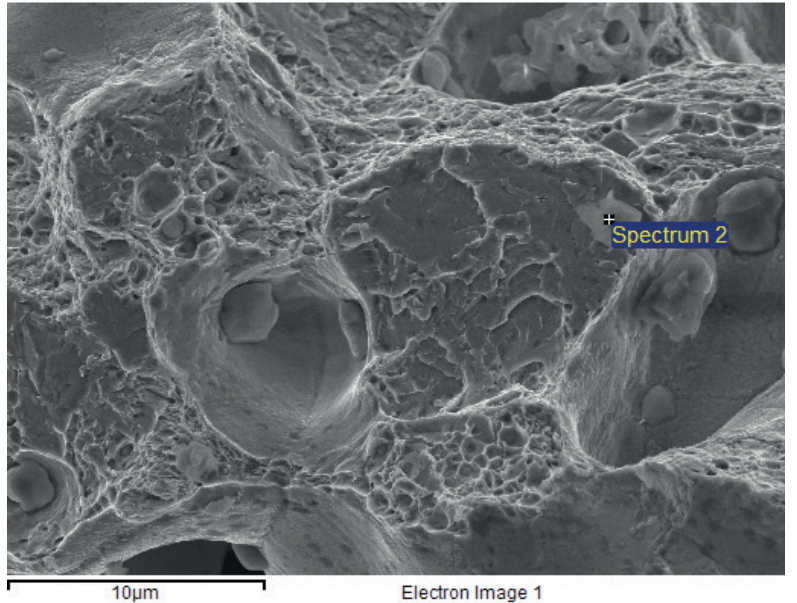

a)

\begin{tabular}{|c|c|c|}
\hline \multirow{2}{*}{ Spectrum 2 } & \multicolumn{2}{|c|}{ Element } \\
\cline { 2 - 3 } & wt.-\% & at.-\% \\
\hline $\mathbf{C}$ & 4.11 & 7.55 \\
\hline $\mathbf{O}$ & 36.16 & 49.86 \\
\hline $\mathbf{F}$ & 4.04 & 4.69 \\
\hline $\mathbf{M g}$ & 18.30 & 16.61 \\
\hline $\mathbf{S i}$ & 15.57 & 12.23 \\
\hline $\mathbf{C a}$ & 2.03 & 1.12 \\
\hline $\mathbf{M n}$ & 19.78 & 7.94 \\
\hline
\end{tabular}

Fig. 11. Fractography of sample B6 (a) with EDS analyses of spectrum 2 (b)

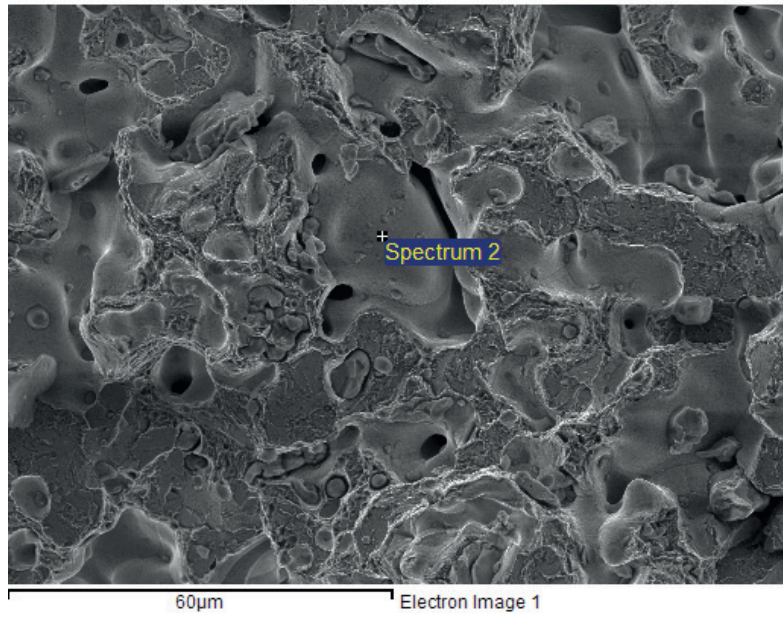

a)

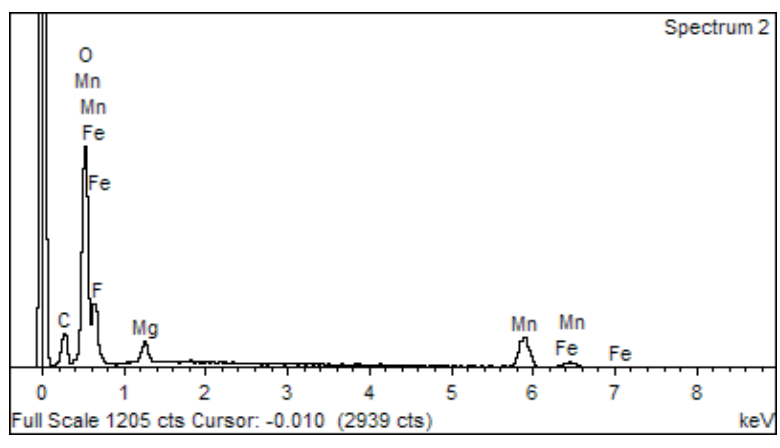

b)

\begin{tabular}{|c|c|c|}
\hline \multirow{2}{*}{ Spectrum 2 } & \multicolumn{2}{|c|}{ Element } \\
\cline { 2 - 3 } & wt.-\% & at.-\% \\
\hline C & 61.22 & 85.91 \\
\hline $\mathbf{O}$ & 3.18 & 3.35 \\
\hline $\mathbf{F e}$ & 35.60 & 10.74 \\
\hline
\end{tabular}

c)

Fig. 12. Fractography of sample B12 (a) with EDS analyses of spectrum 2 (b, c) 


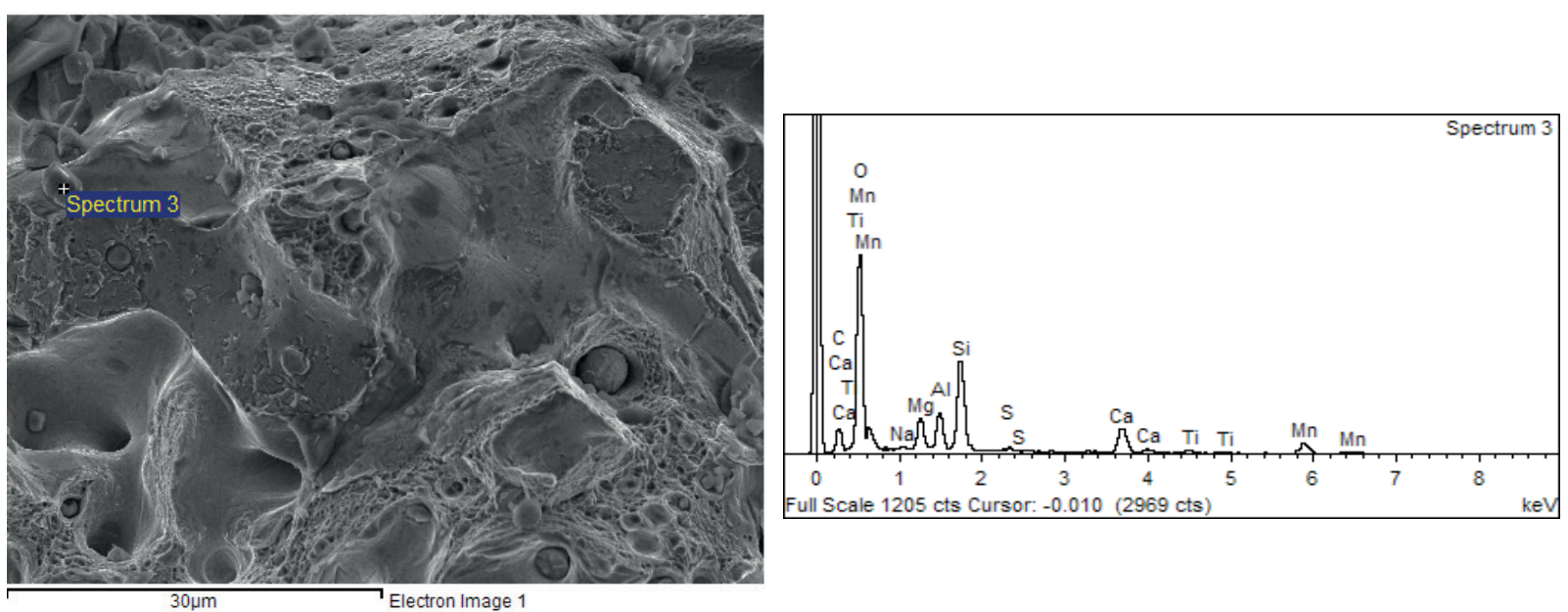

a)

\begin{tabular}{|c|c|c|}
\hline \multirow{2}{*}{ Spectrum 3 } & \multicolumn{2}{|c|}{ Element } \\
\cline { 2 - 3 } & wt.-\% & at.-\% \\
\hline $\mathbf{C}$ & 8.28 & 15.86 \\
\hline $\mathbf{O}$ & 34.28 & 49.28 \\
\hline $\mathbf{N a}$ & 0.46 & 0.46 \\
\hline $\mathbf{M g}$ & 3.76 & 3.56 \\
\hline $\mathbf{A l}$ & 4.51 & 3.84 \\
\hline $\mathbf{S i}$ & 11.97 & 9.80 \\
\hline $\mathbf{S}$ & 0.48 & 0.34 \\
\hline $\mathbf{C a}$ & 9.79 & 5.62 \\
\hline $\mathbf{T i}$ & 2.60 & 1.25 \\
\hline $\mathbf{M n}$ & 23.86 & 9.99 \\
\hline
\end{tabular}

c)

Fig. 13. Fractography of sample B20 (a) with EDS analyses of spectrum 3 (b, c)

\section{Discussion}

Analyzing the results of mechanical tests of sintered manganese steel it was noted that the lowest hardness and tensile strength were recorded for the samples sintered using sinteraustempering treatment in air. During the Vickers hardness test, the best results were obtained for the materials sintered in air using the sinterhardening treatment; satisfactory results were obtained also for all the samples sintered in an atmosphere of $\mathrm{N}_{2}$. The high hardness of sample - sintered, quenched and tempered - could be a result of martensite in the structure.

During the sinterhardening operation, the rapid cooling allow to the martensitic transformation, negligible the atmosphere. During sinteraustempering process there is a slower cooling and the structure was composed mainly of pearlite and ferrite (for samples B1-B5). The presence of ferrite, contributing to a decrease hardness of the material, is associated with decarburization of the material during sintering in the air.

During static tension test there was observed that the highest tensile strength was obtained for the materials sintered in a nitrogen atmosphere. Lower results of tensile strength for manganese steel, sintered in air, caused by excess oxides caused embrittlement of the material resulting from the applied atmosphere. Plastic properties of tensile samples were comparable to each other. Slightly lower relative elongation (Table 6) was characteristic for the samples produced using the SAT in air. During metallographic investigations (Fig. 4-5) it was noted that the sinterhardening procedure favors the formation more martensite in structure. Decarburizing the steel sintered in air hindered the formation of martensite. In addition, because in the sinteraustempering method is used slower cooling with bainitic endurance, in sample B12 a smaller amount of martensite (in comparison with a sample of B20 which was prepared using the variant SH in N2 ) was observed in the structure, but also a bainite. The analyses of the microstructure of samples P2, P8, P13 and P18 shown the advantage in the presence of a pearlite structure. These materials were sintered at $1120^{\circ} \mathrm{C}$. In samples marked $\mathrm{P}$, sintered in a $\mathrm{N}_{2}$ atmosphere, (ie. P8 and P18) small amounts of martensite was found. Probably this is due to the lack of uniform structure after sintering (lack of complete solubility of carbon), which is conditioned of too low sintering temperature. The advantage of the presence of intergranular fracture is caused by formation of neck filled with oxides. Locally neck initiate the formation of the flat 
dimples which indicate the presence of a ductile fracture. In some places, extension of the neck is noticeable, caused by plastic deformation. Occasionally, cracking in the structure of pearlite and bainite was observed. Rarely observed was cleavage in the martensite and bainite. The most brittle fracture was observed for sample B12.

To the comparative analysis, mentioned samples were used: B3, B12, B6, B20 and P2, P8, P13 and P18. Table 2 shows the summary of the measurements of the mechanical properties of the compared samples. The samples are collected in pairs because of the similarity of the production parameters. The analysis the results mentioned above shows that the samples sintered at higher temperatures possessed higher hardness, irrespective of the sintering process. Strength properties in most cases were better for the samples sintered at $1120^{\circ} \mathrm{C}$.

Comparing the test results for samples manufactured using the SAT treatment it was concluded that the most favorable properties of the materials are prepared in the embodiment $1120^{\circ} / \mathrm{SAT} / \mathrm{N} 2$. For sinterhardening, the best results was obtained for the variant $1120^{\circ} / \mathrm{SH} / \mathrm{N} 2$. The observed microstructure was much more favorable for the material sintered at higher temperatures. In the case of sintering at $1250^{\circ} \mathrm{C}$, even after SAT treatment, martensitic structure appeared (the atmosphere of nitrogen was necessary for this). In the case of sintering at $1120^{\circ} \mathrm{C}$, the presence of martensite in the structure was observed only by using the SH treatment. During the fractography observation in both, SAT and SH, the presence of large amounts of oxides was observed. Using of the bainitic endurance did not help in the reduction of oxides. Sintering at a lower temperature allowed to obtain an advantage of ductile fracture due to the presence of pearlite and bainite structure.

\section{Conclusions}

It was noted by analyzing fractography that, although the microstructure of the sintered manganese steel seemed to be optimum, the samples were characterized by a large amount of brittle fracture, because of too much oxides. The sintering temperature $1250^{\circ} \mathrm{C}$ was not enough for manganese oxide reduction. Sinteraustempering treatment reduced mechanical properties of the steels - in particular in combination with air atmosphere during sintering. The use of $\mathrm{N}_{2}$ was more favourable for both the sinterhardening and sinteraustempering treatments. Comparing the results of this study and studies $[9,10]$ it was concluded that the higher temperature was not beneficial for mechanical properties of sintered steel.

\section{Acknowledgments}

The authors are grateful to dr M. Kupkova, dr E. Dudrova and M. Kabatova from IMR SAS, Kosice, Slovakia for their scientific discussion, helpful advice and contribution to material testing.

The financial support of the Ministry of Science and Higher Education under AGH contract no 11.11.110.299 is gratefully acknowledged.

Appreciation is also expressed to Prof. A.S. Wronski for his advice and comments on the manuscript, as well as its editing.

\section{REFERENCES}

[1] E. Dudrova, M. Kabatova, Powder Metallurgy Training Courses, Germany 3-11 September 2005, EMPA.

[2] A. Romański. Optimization of the Chemical Composition and Manufacturing Parameters of Sintered Fe-Mn-Mo-C Steel. PhD. Thesis, AGH UST, Cracow (2000).

[3] P.K. Jones, K. Buckley-Golder, H. David, R. Lawcock, D Sarafinchan, R. Shivanath, L. Yao, in: Proc. of 1998 World PM Congress, 155 (1998).

[4] M. Sulowski, M. Kabatova, E. Dudrova, Powder Metallurgy Progress 12, (2), 71-83 (2012).

[5] S. Cygan, M. Sułowski, M. Ciesielka, Ores and Non-ferrous Metals R57, (9), 609-614 (2012).

[6] P. Gac, M. Sułowski, M. Ciesielka, Ores and Non-ferrous Metals R57, (10), 712-717 (2012).

[7] M. Sulowski, M. Kabatova, E. Dudrova, Acta Metallurgica Slovaca - Conference 3, 237-246 (2013).

[8] E. Chudzik, M. Sułowski, M. Ciesielka, Ores and Non-ferrous Metals R58, (6), 326-332 (2013).

[9] E. Lichańska, M. Sułowski, M. Ciesielka, Ores and Nonferrous Metals R58, (9), 514-520 (2013).

[10] T. Pieczonka, M. Sułowski, A. Ciaś, Archives of Metallurgy and Materials 57, (24), 71001-1009 (2012).

[11] M. Sułowski, Powder Metallurgy 53, (2), 125-140 (2010).

[12] Ch. Fiał, E. Dudrová, M. Kabátová, M. Kupková, M. Selecká, M. Sułowski, A. Ciaś, Powder Metallurgy Progress 15, special issue, 124-129 (2015).

[13] Ch. Fiał, E. Dudrová, M. Kabátová, M. Kupková, M. Selecká, M. Sułowski, A. Ciaś, Powder Metallurgy Progress 14, (3), 137-147 (2014).

[14] A. Ciaś, Science of Sintering 47, (1), 61-69 (2015)

[15] P. Hebda. Sinteraustempering of manganese steels sintered in $1120^{\circ} \mathrm{C}$. Master Thesis, AGH, Cracow, 2014.

[16] B. Milewski. Influence of sintering atmosphere on mechanical properties and microstructure of sintered manganese steel. Master Thesis, AGH, Cracow, 2014. 